\title{
Digital Droplet PCR-Based Environmental DNA Tool for Monitoring Cryptocaryon irritans in a Marine Fish Farm from Hong Kong
}

\author{
Hin Hung Tsang ${ }^{1,2}$, Jose A. Domingos ${ }^{3}{ }^{\mathbb{D}}$, Jacob A. F. Westaway ${ }^{4,5,6}$, Maximilian H. Y. Kam ${ }^{2}$, \\ Roger Huerlimann $5,7,8(D)$ and Giana Bastos Gomes ${ }^{2,9, *}$
}

check for updates

Citation: Tsang, H.H.; Domingos, J.A.; Westaway, J.A.F.; Kam, M.H.Y.; Huerlimann, R.; Bastos Gomes, G. Digital Droplet PCR-Based

Environmental DNA Tool for Monitoring Cryptocaryon irritans in a Marine Fish Farm from Hong Kong. Diversity 2021, 13, 350. https:// doi.org $/ 10.3390 / \mathrm{d} 13080350$

Academic Editors: Karl Cottenie and Michael Wink

Received: 6 July 2021

Accepted: 27 July 2021

Published: 29 July 2021

Publisher's Note: MDPI stays neutral with regard to jurisdictional claims in published maps and institutional affiliations.

Copyright: (c) 2021 by the authors Licensee MDPI, Basel, Switzerland. This article is an open access article distributed under the terms and conditions of the Creative Commons Attribution (CC BY) license (https:// creativecommons.org/licenses/by/ $4.0 /$ )
1 Simon F.S. Li Marine Science Laboratory, School of Life Sciences, The Chinese University of Hong Kong, Hong Kong, China; hhtsang@link.cuhk.edu.hk

2 Department of Infectious Diseases and Public Health, Jockey Club College of Veterinary Medicine and Life Sciences, City University of Hong Kong, Hong Kong, China; maximkam@cityu.edu.hk

3 Tropical Futures Institute, James Cook University Singapore, Singapore 387380, Singapore; jose.domingos1@jcu.edu.au

4 College of Public Health, Medical and Veterinary Science, James Cook University, 1/14-88 7 McGregor Road, Smithfield, QLD 4878, Australia; jacob.westaway@my.jcu.edu.au

5 Centre for Tropical Bioinformatics and Molecular Biology, James Cook University, James Cook Dr, Douglas, QLD 4811, Australia; ROGER.HUERLIMANN@oist.jp

6 Menzies School of Health Research, John Mathews Building (58), Royal Darwin Hospital Campus, Rocklands Drive, Casurina, NT 0810, Australia

7 College of Science and Engineering, James Cook University, 1 James Cook Dr, Douglas, QLD 4811, Australia

8 Marine Climate Change Unit, Okinawa Institute of Science and Technology (OIST), 1919-1 Tancha, Onna-son, Okinawa 904-0495, Japan

9 Temasek Life Sciences Laboratory, 1 Research Link, National University of Singapore, Singapore 117604, Singapore

* Correspondence: giana@tll.org.sg

Abstract: The adoption of new investigative strategies based on environmental DNA (eDNA) can be used to monitor parasites, associated bacterial microbiomes, and physical-chemical parameters in fish farms. In this study, we used the economically important and globally distributed fish ciliate parasite Cryptocaryon irritans as a model to understand the parasite abundance and potential drivers of its presence in marine fish farms. Environmental (rainfall) and physical-chemical (temperature, oxygen, salinity, $\mathrm{pH}$ ) data collected from a marine fish farm in Hong Kong were analyzed together with the eDNA approach targeting $C$. irritans abundance based on digital droplet PCR and 16S metagenomics to determine associations and triggers between parasites and specific bacterial groups. Rainfall and temperature demonstrated positive associations with high abundance of $C$. irritans (eDNA) at the studied marine fish cage farm. However, rainfall was the only parameter tested that demonstrated a significant association with parasite eDNA, indicating that the raining season is a risky period for fish farmers in Hong Kong. Coraliomargarita was the bacterial genus with the most significant relationship with low abundance of $C$. irritans in water. Understanding the environmental triggers of ciliate parasites propagation and associated bacterial microbiome could elucidate new insights into environmental control, microbial management, and promote the reduction of chemical use in marine fish farms.

Keywords: aquaculture; bacterial microbiome; biomonitoring; ciliate parasites; eDNA; marine fish parasite

\section{Introduction}

The aquatic environment in marine fish farms is complex and interactive. These farms are exposed to multiple aquatic microbes which propagate and co-exist with fish [1-3]. Recent studies have started to unveil close relationships between the bacterial microbiomes 
and the proliferation of parasitic ciliates within aquatic environments [3,4]. However, limited knowledge exists on the interaction between ciliate protozoan and bacterial communities in marine fish farms specifically. Some of these interactions can increase stress, compromise immune capacity, and reduce fish's ability to fight infections, while the exact triggers behind such interactions are usually difficult to determine as a series of abiotic (e.g., water parameters, water current, weather) and biotic (e.g., bacteria responsible for nitrogen cycle) factors can influence the multiplication of these microorganisms [3,5]. Secondary co-infections caused by bacteria during parasitic outbreaks are commonly reported due to damage to skin or compromise of fish's immunity [6]. However, the processes behind such interactions are largely unknown in marine environment [5].

Environmental parameters and organic matter accumulated in fish farms influence the diversity and levels of microorganisms in water $[3,5]$. As microorganisms in aquatic systems are interacting with each other and potential hosts, many of them can directly influence physical-chemical parameters and vice-versa, increasing the risk of diseases within farms $[1,3]$. Therefore, it is unsurprising that the proliferation of pathogenic parasites, including ciliate protozoans, and fish mortalities have been correlated with water quality, environmental parameters, and the bacterial microbiome within culture systems [3,7-9].

Cryptocaryon irritans is an economically important ciliate parasite affecting marine fish globally [10-12]. This ciliate parasite is responsible for cryptocaryonosis (marine white spot disease), an important disease of ornamental, wild, and food fish. Cryptocaryonosis is a significant problem in commercial mariculture, particularly due the nature of aquaculture set ups where the high fish density, parasites, and high organic matter interact [13]. Cryptocaryon irritans severely impairs the skin and gill function of a wide range of marine farmed fish such as orange-spotted grouper (Epinephelus coioides), barramundi (Lates calcarifer), pompano (Trachinotus ovatus), and golden snapper (Lutianus johni) [14,15]. As many other ciliate parasites, $C$. irritans is of particular concern to the aquaculture food industry due its fast propagation in the culture environment without any warning [15]. Once present in aquaculture systems, it is very difficult to eradicate $C$. irritans due to its complex life cycle, hence the importance of pre-emptive measures to avoid outbreaks.

The growth and proliferation of $C$. irritans have been shown to be intrinsically linked to bacterial pathogens such as Vibrio harveyi and Staphylococcus aureus through endosymbiotic relationships [4,6]. Both $C$. irritans and $V$. harveyi infect the tissues of Larimichthys crocea while $C$. irritans further feeds on $V$. harveyi-infected tissues and swallows $V$. harveyi, enabling secondary bacterial infection of affected tissues in fishes $[6,16]$. Environmental and physicalchemical parameters can also influence the proliferation of $C$. irritans [17]. Fluctuations in dissolved oxygen levels such as hypoxic and hyperoxic conditions can affect the growth of $C$. irritans and in some cases, a steady increase in oxygen levels can trigger outbreaks of cryptocaryonosis $[18,19]$. In relation to $C$. irritans complex life cycle, the development of trophonts, division, and release of the infective tomites are generally promoted by warmer temperatures with a lower threshold of $18-20^{\circ} \mathrm{C}$, whereas the reduced salinity (usually below $15 \mathrm{ppt}$ ) causes cytolysis of trophonts and tomonts, restricting the outbreak of cryptocaryonosis $[17,20,21]$. Therefore, the development of an early detection system of this parasite combined with water quality, environmental monitoring, and bacterial microbiome could help to prevent $C$. irritans outbreaks in aquaculture farms.

One promising technique to help with this challenge is a front-line method known as environmental DNA (eDNA), which can detect the genetic material of macro- and microorganisms present in the environment (water or sediment). While the detection of species-specific eDNA has been applied in many studies including aquaculture [22,23], conservation [24,25], physical-chemical parameters assessment [26], and recent screening of the novel coronavirus [27], eDNA has rarely been used as a non-destructive tool to monitor pathogens and parasite abundance in fish farms [28]. In contrast to conventional diagnostic techniques such as histopathology, microbiology, and conventional PCR which detect the infectious agent once the animals are already infected, the eDNA methodology can be used with qPCR and droplet digital PCR techniques to quantify the genetic material of different 
pathogens and parasites in fish farms before animals show disease symptoms [28]. As disease outbreaks are not solely caused by the presence of a pathogen/parasite, but by its combination with the susceptibility of the animals (health status, microbiome community), and the quality of their environment (physical-chemical variables), it is possible to use quantification of pathogens/parasites eDNA to predict diseases outbreaks in aquaculture before sick animals present themselves.

Droplet digital PCR (ddPCR) is a novel tool to quantify the absolute number of specific DNA sequences at very low concentrations $[25,29,30]$. Replicates of conventional qPCR cannot resolve the "concentration plateau" problem due to the sample variability at low DNA concentrations, commonly found in eDNA studies, yet ddPCR circumvents these limitations due to the increased sensitivity and dilution of PCR inhibitors through partitioning a single sample into thousands of droplets which run in parallel $[26,30]$. The nanodroplet PCR reactions are independent, single amplification events. The ddPCR technology has been shown to have higher accuracy in abundance estimation, producing more precise, reproducible, and statistically significant results [31,32]. Recently, ddPCR has also been applied to quantify water and foodborne noroviruses concentrations from water samples [26]. In the case of C. irritans infections, only the trophont or "feeding" stage is the most observable on fish [13]. However, the characteristic white spots may not always be obvious to farmers before mass mortalities are observed [33]. Hence, eDNA method coupled with ddPCR could potentially allow for accurate and early quantification of parasite loads in farming systems without its visible presence.

In the present study, a ddPCR assay for the detection C. irritans from water samples (eDNA) was developed to determine its absolute abundance in a marine fish farm from Hong Kong. Additionally, in order to understand the potential drivers behind the C. irritans abundance in the environment, we assessed its relationship with physical-chemical and environmental parameters, as well as the associated bacterial microbiome. The application of this novel approach demonstrates its potential as a promising environmental monitoring and management tool for mitigating risks of disease outbreaks in commercial fish farms. This important information can also be adopted by environmental and governmental agencies for policy development and regulation of new aquaculture sites and environmental protection.

\section{Materials and Methods}

\subsection{Farm Selection, Fish Species, and Parasite Identification}

A marine fish farm located at Three Fathoms Cove, Hong Kong reporting yearly mortalities with C. irritans was adopted as the location for this study. Cages contained pompano (Trachinotus blochii), Chinese bahaba (Bahaba taipingensis), and rabbitfish (Siganus fuscescens). T. blochii, which was more susceptible to $C$. irritans infections, were transferred across the net-pen cages, while $B$. taipingensis was added during the sampling period. This is a common practice adopted by farmers in Hong Kong and China to help reduce infections (moving fish around may have a "dilution" factor on infections) caused by parasites and other pathogens [34]. In this site, severe mortalities of juvenile T. blochii caused by C. irritans were reported by the farmer and diagnostics confirmed through the ambulatory of veterinary services of the Jockey Club College of Veterinary Medicine and Life Sciences from City University of Hong Kong (Figure 1a).

\subsection{Water Sample Collection}

Water samples were collected weekly between January and August 2020 from five net-pen cages located on the commercial fish farm described in 2.1 (Figure 1b,c). One liter of water sample was collected from each of the five sea cages approximately $50 \mathrm{~cm}$ below the water surface using plastic bottles which were previously sterilized with $10 \%$ bleach. To ensure there was no cross-contamination among water samples during sampling and DNA extraction, negative controls (field blank, Figure 1d) were deployed. In each sampling event, five field blanks consisted of the same plastic bottle used in the field sampling with 
one liter of tap water each and briefly submerged into the farm cages. The field blanks were filtered the same way as the water sample and included in each extraction batch. All samples were stored on ice and transported immediately for processing at the laboratory for Infectious Diseases and Public Health Department at City University of Hong.
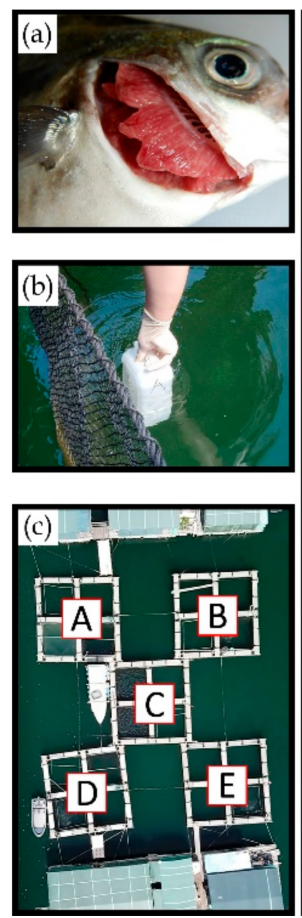

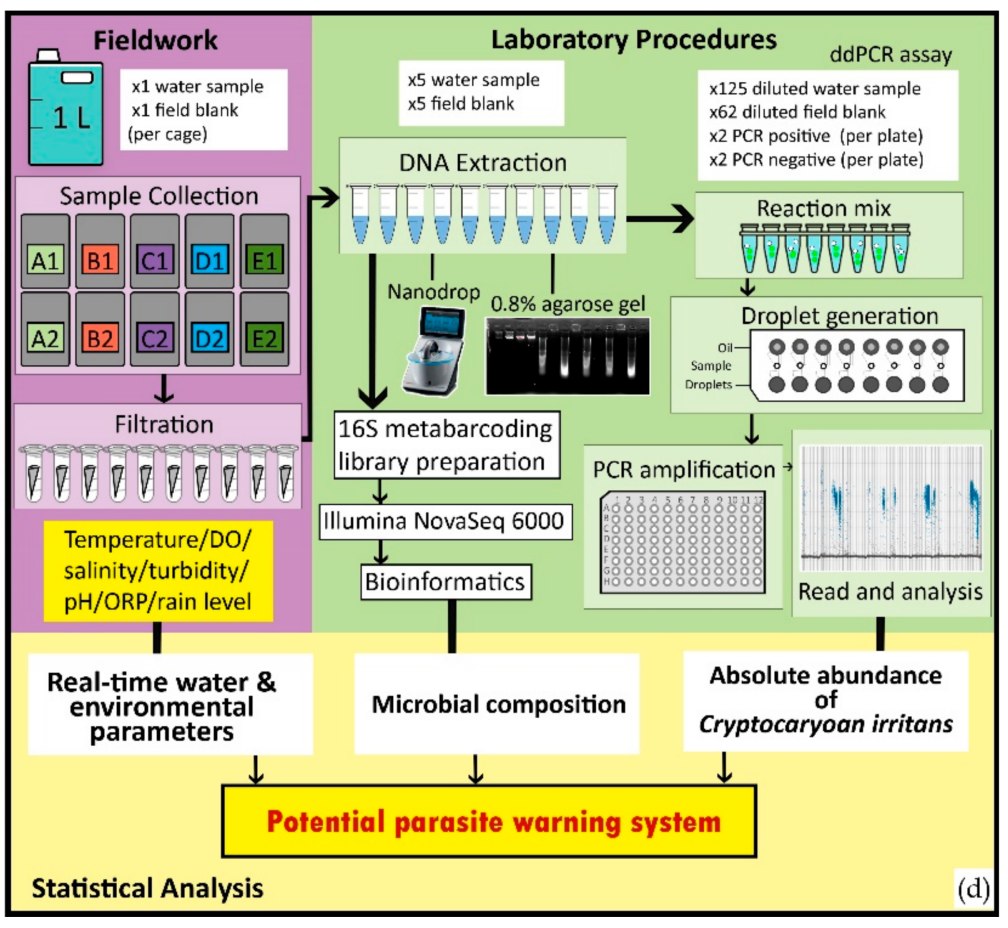

d)

Figure 1. Field sampling from a marine net-pen fish farm in Hong Kong and the systematic workflow: (a) Gills from juvenile pompano (Trachinotus blochii) infected by Cryptocaryon irritans used for confirmation of infection caused by this parasite; (b) collection of water approximately $50 \mathrm{~cm}$ below the water surface; (c) drone overview of the sampling net-pens A-E; and (d) graphical illustration of the key experimental procedures. DO, ORP, PCR, and ddPCR are abbreviations of dissolved oxygen, oxidizing or reducing potential, polymerase chain reaction and droplet digital polymerase chain reaction respectively.

\subsection{Environmental and Physical-Chemical Parameters Measurement}

A series of physical-chemical and environmental parameters were collected by the In-Situ's Aqua TROLL 500 Multiparameter Sondes and HydroMace data loggers (InSitu Inc., Waltham, MA, USA), together with rain gauges installed at the farm study site. Temperature, dissolved oxygen, salinity, turbidity, $\mathrm{pH}$, ORP (oxidizing or reducing potential), and rain levels were collected in real-time via the In-Situ's data services platform every five minutes during the entire 7-month study period. Data were transmitted from the farm site via telemetry to HydroVu and was accessed on-line in real time.

\subsection{Environmental DNA (eDNA) Filtration, Extraction, and Parasite Assay}

Each one liter water sample was pumped through a $3 \mu \mathrm{m}, 47 \mathrm{~mm}$ diameter cellulose nitrate membrane (GE Whatman) using a portable vacuum pump system (Grover Scientific, Rosslea, Australia). Filter membranes were stored in a $1.5 \mathrm{~mL}$ Eppendorf tube at $-20{ }^{\circ} \mathrm{C}$ for DNA extraction. All equipment (vacuum pump, forceps and extension pipes) were cleaned using $10 \%$ bleach for three minutes and then rinsed with tap water for five minutes between each filtration to prevent cross-contamination. The genetic material from half of each filter membrane was extracted using a CTAB (cetyl trimethyl ammonium bromide) DNA extraction protocol described in Bastos Gomes et al. [35] and resuspended in $50 \mu \mathrm{L}$ of $1 X$ TE buffer. The DNA quality was checked by a $0.8 \%$ agarose gel and the DNA was quantified with NanoDrop spectrometer (Thermofisher Scientific, Waltham, MA, USA). 
A specific $C$. irritans TaqMan assay (Thermofisher Scientific, USA; Table 1) was developed based on the SSU-rDNA sequence of $C$. irritans obtained from infected Asian Seabass (Lates calcarifer) from an Australian marine farm (data not published) to quantify the absolute copy numbers in water samples by ddPCR.

Table 1. Specific primers and probes (TaqMan assay) to target SSU-rDNA gene from C. irritans for quantitative PCR and droplet digital PCR.

\begin{tabular}{ccc}
\hline Primer/Probe & Primer/Probe Sequence $5^{\prime} \rightarrow \mathbf{3}^{\prime}$ & Length (bp) \\
\hline FCrypto Primer & TACGTCCCTGCCCTTTGTACA & 84 \\
RCypto Primer & CAGTGTTAGCGCAGTCCAGAAG & \\
Crypto Probe & CCGTCGCTCCTACCGA-FAM & \\
\hline
\end{tabular}

\subsection{Droplet Digital PCR (ddPCR) Assay}

The working area (bench and fume hood) was sterilized with 10\% bleach and $70 \%$ ethanol before every assay set up. All equipment (pipettes, filter tips, ultra-pure water, tube racks, tubes, well plates) were UV-sterilized for $30 \mathrm{~min}$ prior to use. DNA extracts were diluted ten-fold with ultra-pure distilled water (Invitrogen, USA). ddPCR was performed on a QX200 Droplet Digital PCR (Bio-Rad Laboratories, Inc., Hercules, CA, USA) according to the manufacturer's instructions. In summary, ddPCR reactions consisted of $10 \mu \mathrm{L} 2 \mathrm{X}$ ddPCR Supermix for Probes (Bio-Rad Laboratories, Inc., USA), $1 \mu \mathrm{L}$ of TaqMan assay (TaqMan, Thermofisher Scientific, USA), and $9 \mu \mathrm{L}$ of diluted DNA sample. For ddPCR negative controls, the $9 \mu \mathrm{L}$ DNA samples were replaced by the same volume of ultra-pure distilled water. The positive control corresponded to $5.85 \times 10^{13}$ copies $/ \mu \mathrm{L}$ (synthetic sequence of the SSU-rDNA gene from $C$. irritans based on isolates from infected barramundi L. calcarifer (Supplementary Table S1)) was diluted six times using a 100-fold serial dilution to achieve 58.5 copies $/ \mu \mathrm{L}$. Sixty-two field blanks (around 25\% (62 samples) of all extracted samples) were randomly selected for ddPCR to detect any cross-contamination during sample processing. An 8-well cartridge was loaded with $20 \mu \mathrm{L}$ of the reaction mixture and $70 \mu \mathrm{L}$ of oil for droplet generation, in which $40 \mu \mathrm{L}$ of droplet emulsion was pipetted into a 96-well plate. The plate was sealed by a pierceable foil heat seal, and then amplified in C1000 Touch Thermocycler (Bio-Rad Laboratories, Inc., USA) using the following conditions: activation at $95^{\circ} \mathrm{C}$ for $10 \mathrm{~min}, 40$ cycles of $94^{\circ} \mathrm{C}$ for $30 \mathrm{~s}$ and $60^{\circ} \mathrm{C}$ for $1 \mathrm{~min}$, followed by enzyme deactivation at $98^{\circ} \mathrm{C}$ for $10 \mathrm{~min}$ and held at $4{ }^{\circ} \mathrm{C}$ for $30 \mathrm{~min}$. The droplets were read by a QX200 droplet reader and the concentration (absolute count of copies $/ \mu \mathrm{L}$ ) was analyzed by the QuantaSoft Analysis Pro Software (Bio-Rad Laboratories, Inc., USA). Droplets were considered positive when the background threshold limit (the cut-off value of positive droplets) was above 2000 (fluorescence unit). The quality control of reactions was defined as $>16,000$ droplets in each well and $<5$ positive droplets in the negative controls. The copy number of DNA was assumed to have a Poisson distribution; hence the lower limit of detection (LLOD) was interpreted by at least five positive droplets and the upper limit of detection (ULOD) by at least five negative droplets $[30,36]$. The total copy number presented in the one liter water sample $(x)$ was determined by the given data of absolute count (in target copies $/ \mu \mathrm{L}$ ), then calculated relative to the total volume of ddPCR reaction $(20 \mu \mathrm{L})$ and the starting volume of samples before DNA extraction from half of a filter membrane (two of $0.5 \mathrm{~L}$ ). The formula was carried out as:

$$
x=\text { absolute count }\left(\text { in } \frac{\text { copies }}{\mu \mathrm{L}}\right) \times 20 \mu \mathrm{L} \times 0.5 \mathrm{~L} \times 2
$$

\subsection{Library Preparation for Bacterial Microbiome Analysis}

The $16 \mathrm{~S}$ metabarcoding library preparation was carried out at Groken Bioscience Ltd. (Hong Kong). The V3 and V4 regions of the $16 \mathrm{~S}$ gene were amplified using the $16 \mathrm{~S}$ Amplicon PCR primers (341F (5'-CCTAYGGGRBGCASCAG-3') and 806R (5'-GGACTACNNGGGTATCTAAT- $\left.3^{\prime}\right)$ ). Amplicon PCR reactions were carried out with Phusion High-Fidelity PCR 
Master Mix (Bio-Rad Laboratories, Inc., USA). The reaction volumes and cycling conditions followed the manufacturer's protocol. Amplicons of $450-550 \mathrm{bp}$ were selected by a $2 \%$ agarose gel and purified with Qiagen Gel Extraction Kit (Qiagen, Germany). The sequencing libraries were generated using NEBNext Ultra DNA Library Prep Kit for Illumina, following manufacturer's protocols and index codes were attached. The library quality was assessed on the Qubit 2.0 Fluorometer (Thermo Scientific, Waltham, MA, USA) and Agilent Bioanalyzer 2100 system. The library was then normalized, pooled, and denatured to be sequenced on a NovoSeq Illumina platform, and 250 bp paired-end reads were generated.

\subsection{Statistical Analysis and Bioinformatics}

The association between the observed variables, and the abundance of $C$. irritans in water, was analyzed by a principal component analysis (PCA). Abundance of $C$. irritans eDNA data was Ln transformed to conform to a normal distribution prior to analysis (Kolmogorov-Smirnov test, $p>0.05$ ). The original set of five variables of interest were reduced into two principal components for which eigenvalues were $>1$ and represented as a two-dimensional plot. To explore the strength, direction and significance of relationships between variables, a correlation matrix based on Spearman rho $(r)$ bivariate analyses was generated.

A heatmap was also generated to explore the relationship between different genera with high and low C. irritans abundance. Genera were normalized with DESeq2's variance stabilizing transformation, and differential abundance testing performed using a likelihood ratio test on the $C$. irritans abundance (high vs. low). The transformed abundances for taxa significantly affected by $C$. irritans were then used to create a matrix with mean abundances for high and low $C$. irritans abundance, with the matrix then applied to the heatmap function with clustering by rows (taxonomy).

Both pre-analytical bioinformatics and statistical analysis were conducted using $\mathrm{R}$ Studio Version 3.6.1 [37] with a pipeline adapted from Workflow for Microbiome Data Analysis: from raw reads to community analyses [38,39]. DADA2 [40] was used for quality filtering and trimming, demultiplexing, denoising, and taxonomic assignment (using the SILVA Database). The microDecon package [41] was used to remove homogenous contamination from samples using blanks. For statistical analysis, a phyloseq object was created using the package Phyloseq [42] with taxa filtered by prevalence (threshold $=0.01$ ) and agglomerated at the genus level.

A generalized logistic regression model (binomial) was used to explore the effect of both the microbiome and environmental parameters on C. irritans abundance (eDNA) (high vs. low) using the package lme4 [43]. Negative-binomial modelling using DESeq2 was used, with its built-in variance stabilizing transformation and likelihood ratio test, to identify genera associated with parasite abundance (eDNA) and that could subsequently be included in the regression model [44]. Both the resulting DESeq2-normalised counts for physical-chemical and environmental parameters were centered and scaled to avoid convergence issues, and multicollinearity assessed, with collinear variables subsequently removed. The resulting fixed factors: dissolved oxygen $(\mathrm{mg} / \mathrm{L})$, rain $(\mathrm{mm})$, salinity (PSU), NS4 marine group (genus), Coraliomargarita (genus), and Arcobacter (genus), as well as the random factor date were included in the model C. irritans (eDNA) (6 Parameters) $+(1 \mid$ Date)

Backwards selection [43-46] was then implemented to simplify the model by comparing Akaike's Information Criterion (AIC) scores between regression models and removing predictors that were not contributing to the model. The final model was Cryptocaryon $(\mathrm{eDNA}) \sim$ rain + dissolved oxygen + NS4 marine group + Coraliomargarita + (1 I Date) The significance of the fixed effects variables in this final model was then assessed using analysis of deviance (Type II Wald Chi-square test) from the car package [45].

\section{Results}

Two main components of a principal component analysis (PCA) explained $71 \%$ of the variances observed among physical-chemical and environmental parameters monitored 
on farm (Figure 2). A positive association was observed between dissolved oxygen and $\mathrm{pH}$ (Figure 2; quadrant I). A positive association was also found among abundance of C. irritans in water (eDNA), rainfall, and water temperature (Figure 2; quadrant II), which were inversely related to salinity (Figure 2; quadrant III), demonstrating that levels of C. irritans were higher during more intensive rain and when temperatures were higher in Hong Kong (summer period in the north hemisphere).

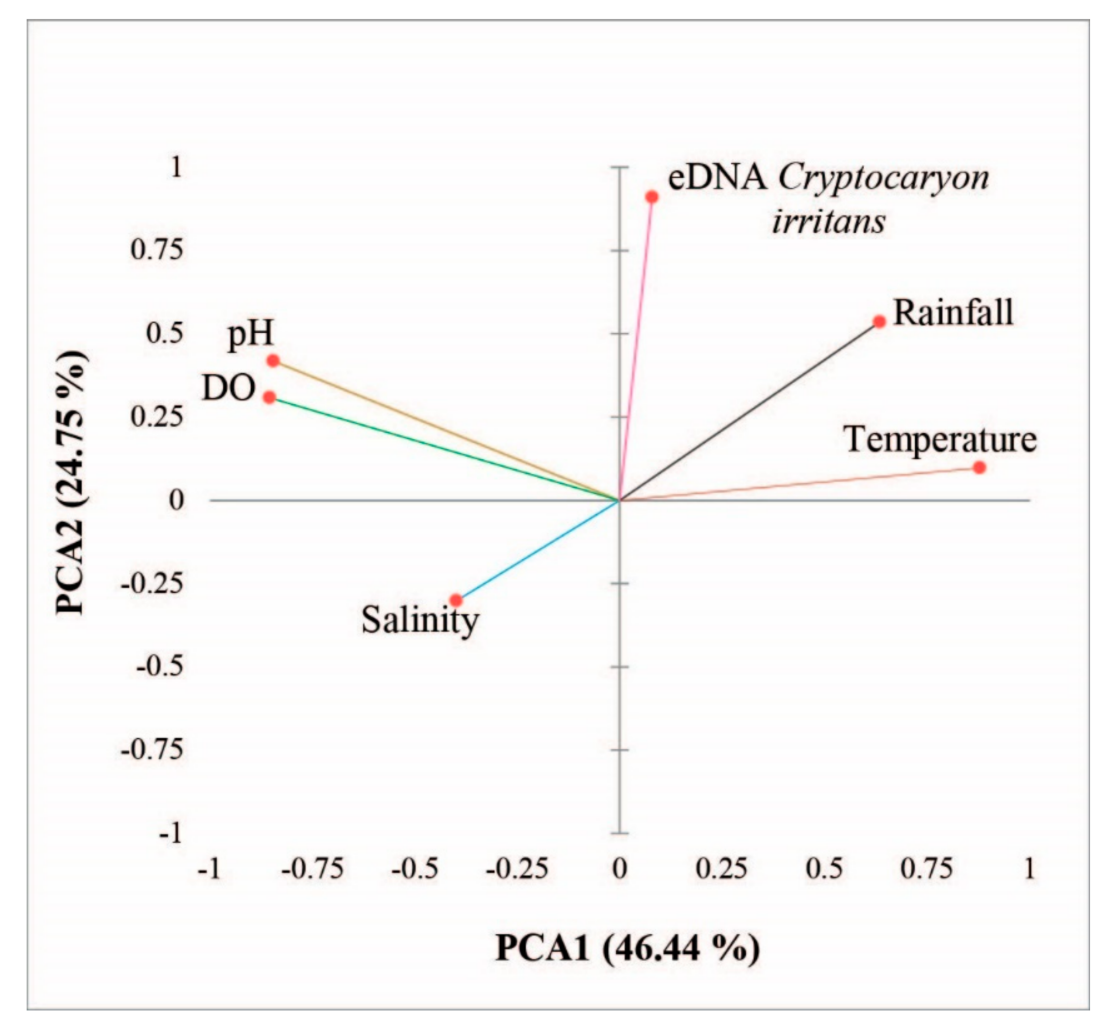

Figure 2. Two most important components of principal component analysis (PCA), showing relationship among variables: abundance of Cryptocaryon irritans water (eDNA), rainfall, temperature, dissolved oxygen, $\mathrm{pH}$, and salinity for five fish sea cages between January and August 2020 from Hong Kong.

Cryptocaryon irritans loads increased between March and May 2020. Figure 3 summarizes the seasonality of $C$. irritans abundance, physical-chemical and the environmental parameters (dissolved oxygen, water temperature, rainfall and salinity) during the seven months period of water collection. C. irritans abundance (eDNA) followed mainly the trends of increasing temperature and rainfall and decreased dissolved oxygen levels. C. irritans loads were particularly high in May 2020, when temperatures surpassed $25^{\circ} \mathrm{C}$, dissolved oxygen readings were consistently dropped below $6 \mathrm{mg} / \mathrm{L}$ and rainfall was intensifying in Hong Kong (Figure 3).

The association among the absolute abundance of C. irritans (eDNA), water quality, environmental parameters, and microbial composition in sea cages from Hong Kong were assessed between January and August 2020. Table 2 summarizes the output for the generalized logistic regression model (GLM) exploring the effects of all biotic (bacterial microbiome) and abiotic variables (physical-chemical and environmental parameters) on high vs. low C. irritans load (eDNA) (based on mean values from seven months of sampling) in water samples, whereas Figure 4 represents the mean $( \pm \mathrm{SD})$ values of each predictor relative to parasite load. 


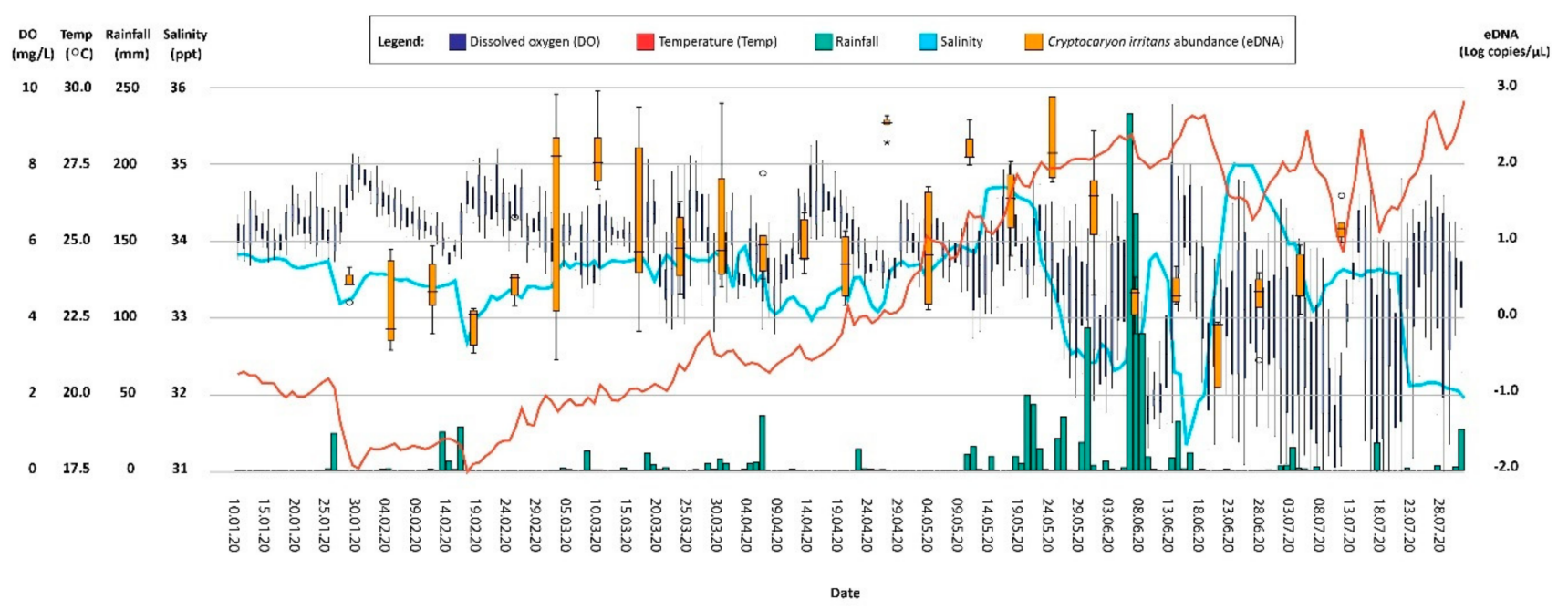

Figure 3. Seasonal changes in the abundance of Cryptocaryon irritans (eDNA) in relation to physical-chemical and environmental parameters: dissolved oxygen (DO), temperature (Temp), rainfall, and salinity for five fish sea cages from Hong Kong between January and August 2020.

Table 2. Statistical summary for the logistic regression with mixed effects model on high vs. low Cryptocaryon irritans load based on bacterial microbiome taxonomy (genus level), environmental parameters from a sea cage fish farm in Hong Kong. Terms bolded indicate significant terms $(p<0.05)$.

\begin{tabular}{cccc}
\hline Predictors & Odd Ratios & $\begin{array}{c}\text { Cryptocaryon irritans } \text { eDNA } \\
\text { Standard Error }\end{array}$ & $p$ \\
\hline Dissolved oxygen & 0.07 & 1.56 & 0.090 \\
Rainfall & 0.08 & 1.22 & $\mathbf{0 . 0 3 4}$ \\
NS4 marine group & 0.10 & 1.30 & 0.081 \\
Coraliomargarita & 2053.29 & 3.51 & $\mathbf{0 . 0 3 0}$ \\
Salinity & 0.31 & 0.94 & 0.208 \\
Arcobacter & 0.33 & 0.97 & 0.253 \\
Observations & 125 & & \\
Marginal & $0.737 / 0.839$ & & \\
$\mathrm{R}^{2}$ Conditional $\mathrm{R}^{2}$ & & & \\
\hline
\end{tabular}

Among the physical-chemical and environmental parameters tested on the farm, rainfall was the only parameter which demonstrated a significant positive association with the abundance of $C$. irritans (eDNA) (Figure 4D), which was also the highest when the abundance of the parasite was high in water. In regards to bacteria identified in the study, the association between high and low parasite load was only significant for Coraliomargarita, for which the relative abundance was high when $C$. irritans eDNA was low (Figure 4A).

The top twenty most abundant bacterial genus for both high and low C. irritans abundance during the seven months period can be observed on the heatmap of Supplementary Figure S1. The relationship between the most significant bacterial genus and high and low abundance of C. irritans (eDNA) are represented in the heatmap of Figure 5. As corroborated by the GLM, Coraliomargarita genus had a relative low abundance when C. irritans was high in the environment during the sampling period of this study. 

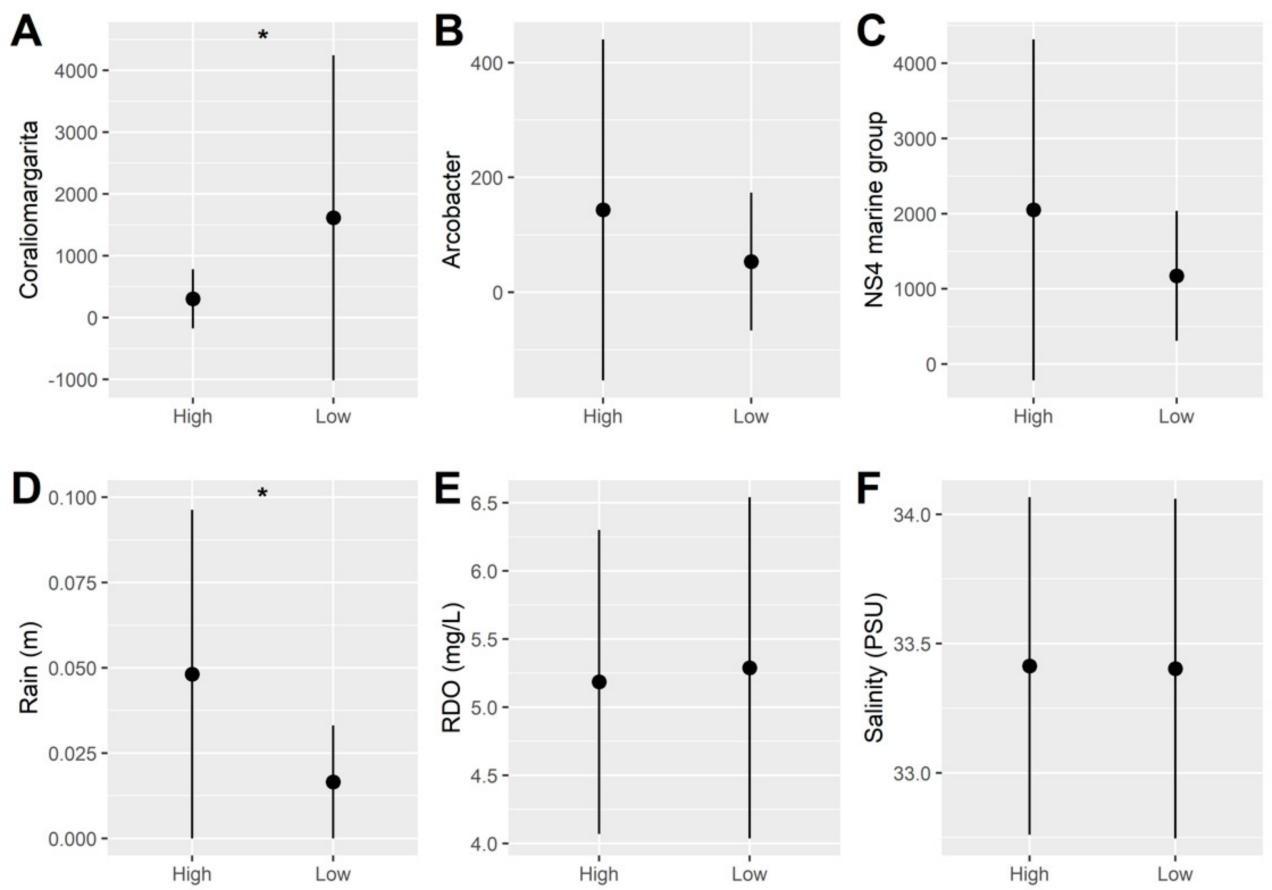

Cryptocaryon irritans abundance (eDNA)

Figure 4. Bar plots showing the mean and standard deviation for factors with significant association with high and low abundance of Cryptocaryon irritans, based on mean values of C. irritans 18S SSUrDNA gene copies/uL calculated using digital droplet PCR quantification) through GLM for a period of seven months in fish cages from Hong Kong. $\left.{ }^{*}=p<0.05\right)$. (A) Coraliomargarita; (B) Arcobacter; and (C) NS4 marine group refer to the bacterial microbiome (genus level -normalized with DESeq2's variance stabilizing transformation). (D) Rain; (E) RDO (rugged dissolved oxygen); and (F) salinity refer to the environmental parameters.

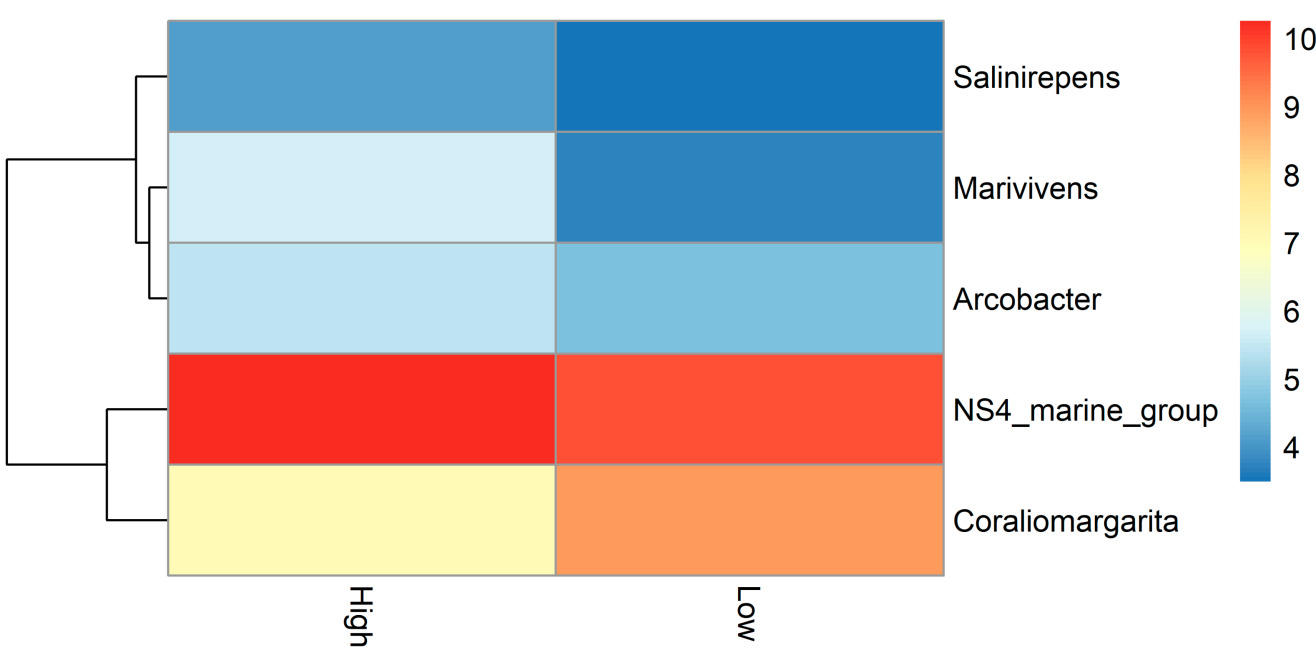

Figure 5. Heatmap clustered by rows showing the DESeq2 normalized abundance of the bacterial gener with a significant relationship with the high and low abundance of $C$. irritans (eDNA- based on mean values of $C$. irritans 18 S SSU-rDNA gene copies/uL using digital droplet PCR quantification) from marine fish sea cages from Hong Kong.

\section{Discussion}

The present study adopted an innovative approach to monitor the marine parasitic protozoan Cryptocaryon irritans based on eDNA-ddPCR approach in a sea cage fish farm 
from Hong Kong between January and August 2020. Additionally, we coupled parasite abundance with the bacterial microbiome (eDNA-NGS of $16 \mathrm{~S}$ gene), physical-chemical and environmental parameters (using sensors data in 5-min intervals) recorded in the same location to understand the drivers of parasite propagation. Cryptocaryonosis has been reported as one of the common parasitic diseases in Hong Kong fish farms [47]. Unfortunately, the participant farm in our study did not monitor fish parasite prevalence or abundance as part of their management practices, which limited our ability to link our physical-chemical and environmental parameters, bacterial microbiome, and C. irritans abundance in water (eDNA) with fish infections or mortalities. The fact that the farm physical-chemical parameters (e.g., dissolved oxygen, temperature) were constantly oscillating along the seven months of sampling, mortalities triggered by these changes together with high loads of $C$. irritans in water could have happened and not being recorded by farmer workers. The lack of fish health monitoring and data records in fish farms seems to be a common trend observed in small scale fish farms of Hong Kong, and South East Asia in general. This fact reinforces the need for the development of indirect ways to identify disease risk (early warning systems) in Asian aquaculture farms.

The difficulty in managing parasite outbreaks in open sea cage fish farms $[10,20]$ could potentially be mitigated by targeted eDNA monitoring strategies associated with physical-chemical and environmental parameters, such as those employed in the present study. In fact, researchers who looked at the ciliate diversity in relation to environmental factors showed that abiotic parameters including water temperature, salinity, $\mathrm{pH}$, and dissolved oxygen are key factors affecting ciliate richness, evenness, and community composition [48]. A recent study of Atlantic salmon (Salmo salar) has demonstrated the role of abiotic parameters in pathogen eDNA collected from seawater similar to our study [49]. Our proposed model (which we acknowledge to be in its exploratory stages) could provide a framework of supportive methods to better understand the complex intricacy between biotic and abiotic factors influencing ciliate dynamics in marine environments. Such framework has strong potential to support the development of warning systems to assist farmers to potentially predict the risk parasites (such as C. irritans) outbreaks, prevent future fish losses and environmental impacts.

Another important aspect of adopting environmental DNA-based monitoring in fish farms is its non-destructive sampling approach [28,50,51]. Traditionally parasites burden is monitored in fish farms by handling animals, use of anesthetics, and preventive bath treatment, which are stressful for fish and can predispose animals getting sick after any of these procedures [52]. Using eDNA-based monitoring tool could bring benefits for farmers with less animal handling, such as lower mortalities due to stress (related to handling). This less aggressive approach could reduce the cost of sampling [53], reduce the use of chemicals, improve animal welfare [54,55], drive positive changes of the bad public perception towards fish farms (related to animal welfare), and support farms with sustainability certification.

In this study a significant relationship between the $C$. irritans abundance and rainfall $(p<0.05)$ was found. Drastic changes in salinities can certainly affect parasite propagation and have a direct association with rainfall. During heavy rainfall periods the salinity measurement in fish farms could decrease to 15 or $10 \mathrm{ppt}$, promoting cytolysis of trophonts and tomonts parasite stages which can significantly cause reduce outbreaks of cryptocaryonosis $[17,20,21]$. However, the observed salinity changes in the present study were potentially not sufficient to cause a disruption in C. irritans development and propagation. Although salinity was inversely related with rainfall, salinity of seawater in the farm area decreased only about 3 ppt overall (i.e., from 34.5 to $31.5 \mathrm{ppt}$ ) in May/June periods of heavier rainfall and higher $C$. irritans abundance. One factor which may have contributed to higher ciliate loads during this rainy period can be explained by a disturbance of the aquatic environment and the sea bed (only five meters deep in the studied farm) through increased nutrient input from surrounding hills and resuspension of organic sediments, which could predispose the propagation of ciliates such as C. irritans. Another potential 
factor for higher ciliate loads identified in periods of heavier rainfall would be directly related to immunity of fish (hosts) farmed within the sampled area. A previous study on the European sea bass (Dicentrarchus labrax) and sea bream (Sparus auratus) reported that fish are weakened during physiological stresses induced by intense precipitation events and become more susceptible to parasites, predisposing fish mortalities [22].

The present study recorded a steady increase in water temperature from March $\left(\sim 20^{\circ} \mathrm{C}\right)$ to June $\left(\sim 28^{\circ} \mathrm{C}\right)$, which coincides with periods of higher levels of $\mathrm{C}$. irritans in water. While in our model temperature was not the most significant parameter to be associated with parasite abundance (perhaps due to only seven months of water sampling), temperature is an important general abiotic factor to consider for the development of any $C$. irritans warning system. The development of trophonts and the division/release of the infective tomites are promoted by warmer temperatures, with optimal growth at $23-30{ }^{\circ} \mathrm{C}[17,21]$; whereas $\mathrm{C}$. irritans can remain dormant in water below $15{ }^{\circ} \mathrm{C}$ [19]. Moreover, there is evidence that prevalence of $C$. irritans can vary widely with seasons as it is temperature dependent $\left(24 \sim 27^{\circ} \mathrm{C}\right)$ and its life cycle can be accelerated at high temperatures (especially over $27^{\circ} \mathrm{C}$ ) $[14,56]$. This fact is particularly important considering the predicted changes in global environmental conditions due to climate change. Increase in water temperatures has caused serious cryptocaryonosis in southern China from spring to autumn [57], which is in agreement with what has been observed through the eDNA approach in the present study.

In relation to the associations observed between bacterial communities, Coraliomargarita genus was significantly associated to the low abundance of C. irritans in water. Based only on our data set, it is difficult to determine the exact reasons for this association as this is the first time that this bacterial genus has been reported in association with ciliate parasites from marine environments. Some coral reef fish seems to harbor Coraliomargarita during larval stage in their gastrointestinal tract, indicating a specific niche for this genus $[58,59]$. This genus could be a common bacterial group found in the waters around the studied farm (shallow area, five meters deep) considering its high organic content and the fact that the farm location has experienced previous algal bloom events (personal communication, farm owner). Uncultured Coraliomargarita genus apparently grows preferentially on high organic compounds which are important indicators of increased phytoplankton concentration and algal blooms, for which this genus was reported to account for $1.15-5.51 \%$ of the bacterial communities in marine cage farms $[60,61]$. The association of Coraliomargarita with algal blooms which are usually triggered by physical-chemical and environmental parameters should be further studied as it may clarify any link of this bacterial group and the abundance of $C$. irritans in marine environments. Furthermore, future studies should integrate data on nutrient concentration in water, turbidity, chlorophyll-a concentration, or even some other indicators of organic matter to clarify the potential link between this bacterial genus and parasites.

Among the most significant bacterial genera associated with the high and low abundance of $C$. irritans, Arcobacter and NS4 marine group were the ones associated with high levels of $C$. irritans in water. Higher $C$. irritans was also associated with relative high levels of NS4 marine group in water. NS4 marine group is another indicator of increased phytoplankton concentration and algal blooms aforementioned [61]. The intensive aquaculture in coastal marine cages caused the dominance of NS4 marine group in Vietnam due to its strong correlations with inorganic nutrients such as ammonium and phosphate (good predictor of algae proliferation) [62]. The Arcobacter genus on the other hand, similarly to Coraliomargarita, is a common bacterial group found in coral reef fish larvae bodies [59]. This genus is one of the food-borne and water-borne human pathogens associated with aquaculture animals representing a serious concern for public health worldwide [63]. Previous studies have showed pathological infections of rainbow trout (Oncorhynchus mykiss) and zebrafish (Danio rerio) with Arcobacter species [64,65]. Given that information related to the functional roles of these two bacterial genera is limited [66], our study may help to 
expand the still limited knowledge base required to implement microbiome management with the goal of predicting the risk of outbreaks in fish farms

\section{Conclusions}

This is the first study to adopt an eDNA-ddPCR-based method to monitor abundance of $C$. irritans in marine waters of Hong Kong. Digital droplet PCR has demonstrated to be an important new tool in clinical microbiology to quantify pathogens [67]. Assays based on ddPCR technology can be more sensitive as a screening tool of species-specific parasites in marine environments, since the end-point quantification method is less affected by inhibitors in water samples compared to conventional quantitative PCR [68-70]. Adopting eDNA quantification based on a ddPCR assays in combination with models of physical-chemical and environmental parameters together with the marine bacterial composition could provide important insights about aquatic animal health and microbial management for the aquaculture industry. While this study reports the first exploratory insights into the relationship between a parasitic ciliate, bacterial communities, and physicalchemical/environmental data analysis from a marine fish farm, this information could be further explored as the basis for the development of environmental policies by government agencies. Furthermore, the proposed model could support companies or governmental agencies on mapping out new aquaculture sites with a focus on environmental protection and sustainability.

Supplementary Materials: The following are available online at https://www.mdpi.com/article/ 10.3390/d13080350/s1. Figure S1: Heatmap clustered by rows showing the DESeq2 normalized abundance of the top twenty most abundant bacterial genus for both high and low (based on mean values) C. irritans abundance (eDNA) between January and August 2020 from a marine sea cage fish farm from Hong Kong. Table S1: Synthetic sequence of the positive control targeting 18S SSU-rDNA gene from C. irritans for quantitative PCR and digital PCR.

Author Contributions: Conceptualization, G.B.G.; methodology, H.H.T. and G.B.G.; software, H.H.T.; validation, H.H.T. and G.B.G.; formal analysis, J.A.D. and J.A.F.W.; investigation, H.H.T. and M.H.Y.K.; resources, G.B.G.; data curation, G.B.G.; writing-original draft preparation, H.H.T. and G.B.G.; writing-review and editing, J.A.D., J.A.F.W., R.H.; visualization, J.A.D. and J.A.F.W.; supervision, G.B.G.; project administration, G.B.G.; funding acquisition, G.B.G. All authors have read and agreed to the published version of the manuscript.

Funding: This research was funded by Sea Pact grant (https:/ /www.seapact.org/) (accessed on 29 July 2021), grant number 9231354_City University of Hong Kong and CityU internal grant 9610448.

Institutional Review Board Statement: Not applicable.

Informed Consent Statement: Not applicable.

Data Availability Statement: The workflow for the bioinformatics and statistical analysis can be found at: https://github.com/JacobAFW/Aquaculture_Project (Westaway, 2021; accessed on 29 July 2021).

Acknowledgments: This project was supported by the Department of Infectious Diseases and Public Health, City University of Hong Kong, Hong Kong. We thank Aqua Millenium farm and Bio-Rad Pacific Ltd. for support and assistance during this study.

Conflicts of Interest: The authors declare no conflict of interest. The funders had no role in the design of the study; in the collection, analyses, or interpretation of data; in the writing of the manuscript, or in the decision to publish the results.

\section{References}

1. Blancheton, J.P.; Attramadal, K.J.K.; Michaud, L.; d'Orbcastel, E.R.; Vadstein, O. Insight into bacterial population in aquaculture systems and its implication. Aquac. Eng. 2013, 53, 30-39. [CrossRef]

2. Salipante, S.J.; Sengupta, D.J.; Rosenthal, C.; Costa, G.; Spangler, J.; Sims, E.H.; Hoffman, N.G. Rapid 16S rRNA next-generation sequencing of polymicrobial clinical samples for diagnosis of complex bacterial infections. PLoS ONE 2013, 8, e65226. [CrossRef] 
3. Bastos Gomes, G.; Hutson, K.S.; Domingos, J.A.; Infante Villamil, S.; Huerlimann, R.; Miller, T.L.; Jerry, D.R. Parasitic protozoan interactions with bacterial microbiome in a tropical fish farm. Aquaculture 2019, 502, 196-201. [CrossRef]

4. Jahangiri, L.; Shinn, A.P.; Pratoomyot, J.; Bastos Gomes, G. Unveiling associations between ciliate parasites and bacterial microbiomes under warm-water fish farm conditions-A review. Rev. Aquac. 2020, 13, 1097-1118. [CrossRef]

5. Kotob, M.H.; Menanteau-Ledouble, S.; Kumar, G.; Abdelzaher, M.; El-Matbouli, M. The impact of co-infections on fish: A review. Vet. Res. 2016, 47, 98. [CrossRef]

6. Qiao, Y.; Wang, J.; Mao, Y.; Liu, M.; Chen, R.; Su, Y.; Zheng, W. Pathogenic bacterium Vibrio harveyi: An endosymbiont in the marine parasitic ciliate protozoan Cryptocaryon irritans. Acta Oceanol. Sin. 2017, 36, 115-119. [CrossRef]

7. Bentzon-Tilia, M.; Sonnenschein, E.C.; Gram, L. Monitoring and managing microbes in aquaculture-Towards a sustainable industry. Microb. Biotechnol. 2016, 9, 576-584. [CrossRef]

8. de Bruijn, I.; Liu, Y.; Wiegertjes, G.F.; Raaijmakers, J.M. Exploring fish microbial communities to mitigate emerging diseases in aquaculture. FEMS Microbiol. Ecol. 2018, 94, 161. [CrossRef] [PubMed]

9. Ortiz-Estrada, Á.M.; Gollas-Galván, T.; Martínez-Córdova, L.R.; Martínez-Porchas, M. Predictive functional profiles using metagenomic 16S rRNA data: A novel approach to understanding the microbial ecology of aquaculture systems. Rev. Aquac. 2019, 11, 234-245. [CrossRef]

10. Colorni, A. Aspects of the biology of Cryptocaryon irritans, and hyposalinity as a control measure in cultured gilt-head sea bream Sparus aurata. Dis. Aquat. Org. 1985, 1, 19-22. [CrossRef]

11. Dickerson, H.W.; Dawe, D. Ichthyophthirius multifiliis and Cryptocaryon irritans (phylum Ciliophora). Fish. Dis. Disord. 2016, 1, 116-153.

12. Standing, D.; Brunner, T.; Aruety, T.; Ronen, Z.; Gross, A.; Zilberg, D. Mortality of Cryptocaryon irritans in sludge from a digester of a marine recirculating aquaculture system. Aquaculture 2017, 467, 134-137. [CrossRef]

13. Van, K.V.; Nhinh, D.T. The prevalence of Cryptocaryon irritans in wild marine ornamental fish from Vietnam. IOP Conf. Ser. Earth Environ. Sci. 2018, 137, 012094. [CrossRef]

14. Dan, X.M.; Li, A.X.; Lin, X.T.; Teng, N.; Zhu, X.Q. A standardized method to propagate Cryptocaryon irritans on a susceptible host pompano Trachinotus ovatus. Aquaculture 2006, 258, 127-133. [CrossRef]

15. Khoo, C.K.; Abdul-Murad, A.M.; Kua, B.C.; Mohd-Adnan, A. Cryptocaryon irritans infection induces the acute phase response in Lates calcarifer: A transcriptomic perspective. Fish Shellfish Immunol. 2012, 33, 788-794. [CrossRef] [PubMed]

16. Nguyen, H.T.; Thu Nguyen, T.T.; Tsai, M.A.; Ya-Zhen, E.; Wang, P.C.; Chen, S.C. A formalin-inactivated vaccine provides good protection against Vibrio harveyi infection in orange-spotted grouper (Epinephelus coioides). Fish Shellfish Immunol. 2017, 65, 118-126. [CrossRef]

17. Diggles, B.K.; Lester, R.J.G. Influence of temperature and host species on the development of Cryptocaryon irritans. J. Parasitol. 1996, 82, 45-51. [CrossRef]

18. Yoshinaga, T. Effects of high temperature and dissolved oxygen concentration on the development of Cryptocaryon irritans (Ciliophora) with a comment on the autumn outbreaks of cryptocaryoniasis. Fish Pathol. 2001, 36, 231-235. [CrossRef]

19. Imajoh, M.; Morimitu, K.; Sukeda, M.; Umezaki, T.; Monno, S.; Goda, H.; Oshima, S.-I. TaqMan real-Time PCR detection and phylogenetic analysis of Cryptocaryon irritans in Nomi Bay, Kochi, Japan. Fish Pathol. 2016, 51, 103-111. [CrossRef]

20. Cheung, P.J.; Nigrelli, R.F.; Ruggieri, G.D. Studies on cryptocaryoniasis in marine fish: Effect of temperature and salinity on the reproductive cycle of Cryptocaryon irritans Brown, 1951. J. Fish Dis. 1979, 2, 93-97. [CrossRef]

21. Burgess, P.; Matthews, R. Cryptocaryon irrttans (Ciliophora): Photoperiod and transmission in marine fish. J. Mar. Biol. Assoc. U. K. 1994, 74, 535-542. [CrossRef]

22. Peters, L.; Spatharis, S.; Dario, M.A.; Dwyer, T.; Roca, I.J.T.; Kintner, A.; Praebel, K. Environmental DNA: A new low-cost monitoring tool for pathogens in salmonid aquaculture. Front. Microbiol. 2018, 9, 3009. [CrossRef]

23. Elberri, A.I.; Galal-Khallaf, A.; Gibreel, S.E.; El-Sakhawy, S.F.; El-Garawani, I.; El-Sayed Hassab ElNabi, S.; Mohammed-Geba, K. DNA and eDNA-based tracking of the North African sharptooth catfish Clarias gariepinus. Mol. Cell. Probes 2020, $51,101535$. [CrossRef]

24. Robson, H.L.; Noble, T.H.; Saunders, R.J.; Robson, S.K.; Burrows, D.W.; Jerry, D.R. Fine-tuning for the tropics: Application of eDNA technology for invasive fish detection in tropical freshwater ecosystems. Mol. Ecol. Resour. 2016, 16, 922-932. [CrossRef] [PubMed]

25. Capo, E.; Spong, G.; Koizumi, S.; Puts, I.; Olajos, F.; Königsson, H.; Byström, P. Droplet digital PCR applied to environmental DNA, a promising method to estimate fish population abundance from humic-rich aquatic ecosystems. Environ. DNA 2020, 3 , 343-352. [CrossRef]

26. Monteiro, S.; Santos, R. Nanofluidic digital PCR for the quantification of Norovirus for water quality assessment. PLoS ONE 2017, 12, e0179985. [CrossRef] [PubMed]

27. Haramoto, E.; Malla, B.; Thakali, O.; Kitajima, M. First environmental surveillance for the presence of SARS-CoV-2 RNA in wastewater and river water in Japan. Sci. Total Environ. 2020, 737, 140405. [CrossRef] [PubMed]

28. Bastos Gomes, G.; Hutson, K.S.; Domingos, J.A.; Chung, C.; Hayward, S.; Miller, T.L.; Jerry, D.R. Use of environmental DNA (eDNA) and water quality data to predict protozoan parasites outbreaks in fish farms. Aquaculture 2017, 479, 467-473. [CrossRef] 
29. Doi, H.; Takahara, T.; Minamoto, T.; Matsuhashi, S.; Uchii, K.; Yamanaka, H. Droplet digital polymerase chain reaction (PCR) outperforms real-time PCR in the detection of environmental DNA from an invasive fish species. Environ. Sci. Technol. 2015, 49, 5601-5608. [CrossRef]

30. Hunter, M.E.; Dorazio, R.M.; Butterfield, J.S.; Meigs-Friend, G.; Nico, L.G.; Ferrante, J.A. Detection limits of quantitative and digital PCR assays and their influence in presence-absence surveys of environmental DNA. Mol. Ecol. Resour. 2017, 17, 221-229. [CrossRef]

31. Doi, H.; Uchii, K.; Takahara, T.; Matsuhashi, S.; Yamanaka, H.; Minamoto, T. Use of droplet digital PCR for estimation of fish abundance and biomass in environmental DNA surveys. PLoS ONE 2015, 10, e0122763. [CrossRef]

32. Taylor, S.C.; Laperriere, G.; Germain, H. Droplet Digital PCR versus qPCR for gene expression analysis with low abundant targets: From variable nonsense to publication quality data. Sci. Rep. 2017, 7, 2409. [CrossRef] [PubMed]

33. Yanong, R.P.E. Cryptocaryon irritans infections (marine white spot disease) in fish. In Program in Fisheries and Aquatic Sciences, SFRC, Florida Cooperative Extension Service; Institute of Food and Agricultural Sciences, University of Florida: Gainesville, FL, USA, 2010.

34. Jiang, B.; Li, Y.W.; Abdullahi, A.Y.; Dan, X.M.; Gong, H.; Ke, Q.Z.; Li, G.Q. Placemat and rotational culturing: A novel method to control Cryptocaryon irritans infection by removing tomonts. Aquaculture 2016, 459, 84-88. [CrossRef]

35. Bastos Gomes, G.; Jerry, D.R.; Miller, T.L.; Hutson, K.S. Current status of parasitic ciliates Chilodonella spp. (Phyllopharyngea: Chilodonellidae) in freshwater fish aquaculture. J. Fish Dis. 2017, 40, 703-715. [CrossRef]

36. Gobert, G.; Cotillard, A.; Fourmestraux, C.; Pruvost, L.; Miguet, J.; Boyer, M. Droplet digital PCR improves absolute quantification of viable lactic acid bacteria in faecal samples. J. Microbiol. Methods 2018, 148, 64-73. [CrossRef]

37. RStudio Team. RStudio: Integrated Development for R. RStudio; PBC: Boston, MA, USA, 2020.

38. Callahan, B.J.; McMurdie, P.J.; Rosen, M.J.; Han, A.W.; Johnson, A.J.A.; Holmes, S.P. DADA2: High-resolution sample inference from Illumina amplicon data. Nat. Methods 2016, 13, 581-583. [CrossRef]

39. Westaway, J. Aquaculture_Project. GitHub Repository 2021. Available online: https:/ /JacobAFW/Aquaculture_Project-github. com/ (accessed on 11 June 2021).

40. Callahan, B.J.; Sankaran, K.; Fukuyama, J.A.; McMurdie, P.J.; Holmes, S.P. Bioconductor workflow for microbiome data analysis: From raw reads to community analyses. F1000Research 2016, 5, 1492. [CrossRef] [PubMed]

41. McKnight, D.T.; Huerlimann, R.; Bower, D.S.; Schwarzkopf, L.; Alford, R.A.; Zenger, K.R. microDecon: A highly accurate read-subtraction tool for the post-sequencing removal of contamination in metabarcoding studies. Environ. DNA 2019, 1, 14-25. [CrossRef]

42. McMurdie, P.J.; Holmes, S. phyloseq: An R package for reproducible interactive analysis and graphics of microbiome census data. PLoS ONE 2013, 8, e61217. [CrossRef]

43. Bates, D.; Mächler, M.; Bolker, B.; Walker, S. Fitting linear mixed-effects models using lme4. arXiv 2014, arXiv:1406.5823.

44. Love, M.I.; Huber, W.; Anders, S. Moderated estimation of fold change and dispersion for RNA-seq data with DESeq2. Genome Biol. 2014, 15, 1-21. [CrossRef]

45. Fox, J.; Weisberg, S. An R Companion to Applied Regression, 4th ed.; Sage Publications: New York, NY, USA, 2018.

46. Saksis, R.; Silamikelis, I.; Laksa, P.; Megnis, K.; Peculis, R.; Mandrika, I.; Konrade, I. Medication for acromegaly reduces expression of MUC16, MACC1 and GRHL2 in pituitary neuroendocrine tumour tissue. Front. Oncol. 2020, 10, 593760. [CrossRef] [PubMed]

47. Chong, R. Pathology of Cultured Fish in Hong Kong, 1st ed.; Agriculture, Fisheries and Conservation Department: Hong Kong, China, 2015; pp. 145-146.

48. Jiang, C.; Liu, B.; Zhang, J.; Gu, S.; Liu, Z.; Wang, X.; Miao, W. Diversity and seasonality dynamics of ciliate communities in four estuaries of Shenzhen, China (South China Sea). J. Mar. Sci. Eng. 2021, 9, 260. [CrossRef]

49. Bass, D.; Stentiford, G.D.; Littlewood, D.T.J.; Hartikainen, H. Diverse Applications of Environmental DNA Methods in Parasitology. Trends Parasitol. 2015, 31, 499-513. [CrossRef] [PubMed]

50. Stentiford, G.D.; Sritunyalucksana, K.; Flegel, T.W.; Williams, B.A.; Withyachumnarnkul, B.; Itsathitphaisarn, O.; Bass, D. New paradigms to help solve the global aquaculture disease crisis. PLoS Pathog. 2017, 13, e1006160. [CrossRef] [PubMed]

51. Shea, D.; Bateman, A.; Li, S.; Tabata, A.; Schulze, A.; Mordecai, G.; Krkosek, M. Environmental DNA from multiple pathogens is elevated near active Atlantic salmon farms. Proc. R. Soc. B 2020, 287, 20202010. [CrossRef]

52. Bonga, S.W. The Stress Response in Fish. Physiol. Rev. 1997, 77, 91-625.

53. European Food Safety Authority (EFSA). Scientific Opinion of the Panel on Biological Hazards on a request from European Commission on Food Safety considerations of animal welfare aspects and husbandry systems for farmed fish. EFSA J. 2008, 867, $1-24$.

54. Bergqvist, J.; Gunnarsson, S. Finfish Aquaculture: Animal Welfare, the Environment, and Ethical Implications. J. Agric. Environ. Ethics 2011, 26, 75-99. [CrossRef]

55. Khalil, R.; Medhat, S.; Hanan, G.; Khallaf, M.; Sherif, S.; Amira, O. Seasonal parasitic infestations and their close relationship to immune suppression in cultured sea bass (Dicentrarchus labrax L.) and sea bream (Sparus auratus). Biomed. J. Sci. Tech. Res. 2018, 6, 5371-5379. [CrossRef]

56. Wang, J.-L.; Lao, G.-F.; Li, Y.-W.; Yang, M.; Mo, Z.-Q.; Dan, X.-M. Effects of temperature and host species on the life cycle of Cryptocaryon irritans. Aquaculture 2018, 485, 49-52. [CrossRef] 
57. Luo, X.C.; Xie, M.Q.; Zhu, X.Q.; Li, A.X. Some characteristics of host-parasite relationship for Cryptocaryon irritans isolated from South China. Parasitol. Res. 2008, 102, 1269-1275. [CrossRef]

58. Parris, D.J.; Brooker, R.M.; Morgan, M.A.; Dixson, D.L.; Stewart, F.J. Whole gut microbiome composition of damselfish and cardinalfish before and after reef settlement. Peer] 2016, 4, e2412. [CrossRef]

59. Yukgehnaish, K.; Kumar, P.; Sivachandran, P.; Marimuthu, K.; Arshad, A.; Paray, B.A.; Arockiaraj, J. Gut microbiota metagenomics in aquaculture: Factors influencing gut microbiome and its physiological role in fish. Rev. Aquac. 2020, 12, 1903-1927. [CrossRef]

60. Hattenrath-Lehmann, T.K.; Jankowiak, J.; Koch, F.; Gobler, C.J. Prokaryotic and eukaryotic microbiomes associated with blooms of the ichthyotoxic dinoflagellate Cochlodinium (Margalefidinium) polykrikoides in New York, USA, estuaries. PLoS ONE 2019, 14, e0223067. [CrossRef]

61. Kolda, A.; Gavrilović, A.; Jug-Dujaković, J.; Ljubešić, Z.; El-Matbouli, M.; Lillehaug, A.; Kapetanović, D. Profiling of bacterial assemblages in the marine cage farm environment, with implications on fish, human and ecosystem health. Ecol. Indic. 2020, 118, 106785. [CrossRef]

62. Kopprio, G.A.; Cuong, L.H.; Luyen, N.D.; Duc, T.M.; Ha, T.H.; Huong, L.M.; Gärdes, A. Carrageenophyte-attached and planktonic bacterial communities in two distinct bays of Vietnam: Eutrophication indicators and insights on ice-ice disease. Ecol. Indic. 2021, 121, 107067. [CrossRef]

63. Rathlavath, S.; Kumar, S.; Nayak, B.B. Comparative isolation and genetic diversity of Arcobacter sp. from fish and the coastal environment. Lett. Appl. Microbiol. 2017, 65, 42-49. [CrossRef] [PubMed]

64. Yildiz, H.; Aydin, S. Pathological effects of Arcobacter cryaerophilus infection in rainbow trout (Oncorhynchus mykiss Walbaum). Acta Vet. Hung. 2006, 54, 191-199. [CrossRef]

65. Overstreet, R.M.; Hawkins, W.E. Diseases and mortalities of fishes and other animals in the Gulf of Mexico. In Habitats and Biota of the Gulf of Mexico: Before the Deepwater Horizon Oil Spill, 1st ed.; Ward, C.H., Ed.; Springer: Berlin, Germany, 2017; pp. 1589-1738.

66. Legrand, T.P.R.A.; Wynne, J.W.; Weyrich, L.S.; Oxley, A.P.A. A microbial sea of possibilities: Current knowledge and prospects for an improved understanding of the fish microbiome. Rev. Aquac. 2019, 12, 1101-1134. [CrossRef]

67. Kuypers, J.; Jerome, K.R. Applications of digital PCR for clinical microbiology. J. Clin. Microbiol. 2017, 55, 1621-1628. [CrossRef] [PubMed]

68. Dingle, T.C.; Sedlak, R.H.; Cook, L.; Jerome, K.R. Tolerance of droplet-digital PCR vs. real-time quantitative PCR to inhibitory substances. Clin. Chem. 2013, 59, 1670-1672. [CrossRef]

69. Rusch, J.C.; Hansen, H.; Strand, D.A.; Markussen, T.; Hytterod, S.; Vralstad, T. Catching the fish with the worm: A case study on eDNA detection of the monogenean parasite Gyrodactylus salaris and two of its hosts, Atlantic salmon (Salmo salar) and rainbow trout (Oncorhynchus mykiss). Parasites Vectors 2018, 11, 333. [CrossRef] [PubMed]

70. Lewin, A.S.; Haugen, T.; Netzer, R.; Tondervik, A.; Dahle, S.W.; Hageskal, G. Multiplex droplet digital PCR assay for detection of Flavobacterium psychrophilum and Yersinia ruckeri in Norwegian aquaculture. J. Microbiol. Methods 2020, 177, 106044. [CrossRef] [PubMed] 